Article

\title{
Life Cycle Assessment of Functional Food: Improving Sustainability in the Biotechnology Industry through Transparency
}

\author{
Alisha Lee *, Yini Wang and Shih-Fang Lo \\ Chung-Hua Institution for Economic Research, Taipei City 10672, Taiwan; yiniwang88@gmail.com (Y.W.); \\ shihfang.lo@cier.edu.tw (S.-F.L.) \\ * Correspondence: alee@cier.edu.tw
}

check for updates

Citation: Lee, A.; Wang, Y.; Lo, S.-F. Life Cycle Assessment of Functional Food: Improving Sustainability in the Biotechnology Industry through Transparency. Processes 2021, 9, 2130. https://doi.org/10.3390/pr9122130

Received: 26 September 2021 Accepted: 24 November 2021 Published: 25 November 2021

Publisher's Note: MDPI stays neutral with regard to jurisdictional claims in published maps and institutional affiliations.

Copyright: (c) 2021 by the authors. Licensee MDPI, Basel, Switzerland. This article is an open access article distributed under the terms and conditions of the Creative Commons Attribution (CC BY) license (https:// creativecommons.org/licenses/by/ $4.0 /)$.

\begin{abstract}
With the advancement of biotechnology, consumers are demanding more scientifically advanced products as well as being more concerned with the environmental impact of products. A life cycle carbon footprint assessment is an important tool in reaching net-zero carbon production goals. This paper presents the greenhouse gas emissions of functional foods by highlighting TCI Co., Ltd. as a case study. TCI conducted life cycle assessments (LCAs) on two mainstream products that utilize common manufacturing processes to examine their carbon footprint and gain a better understanding of their environmental impact. The main finding shows that while the manufacturing stage accounts for around $20-30 \%$ of emissions, the raw material stage accounts for $70-80 \%$ for both products. This suggests that TCI needs to work closely with its suppliers to ensure a low emissions supply chain and to achieve its net-zero target. Not only do these LCAs allow TCI to increase the products' transparency, but they can also be offered as a reference to other businesses producing similar products. Sharing of knowledge and practices in the biotechnology industry benefits the entire ecosystem and improves corporate sustainability.
\end{abstract}

Keywords: life cycle assessment LCA; carbon footprint; biotechnology; functional food; greenhouse gas emissions

\section{Introduction}

To ensure global warming does not exceed 1.5 degrees Celsius, as is the recommendation of the Paris Agreement, companies must assess their greenhouse gas (GHG) emissions to understand how they contribute to the climate crisis and what they can do to minimize emissions. The publication of life-cycle assessment (LCA) results enables transparency and comparison of emissions for similar products, and possibly the improvement in sustainability of such products. Transparency of environmental impacts in an industry is a key step in understanding the industry's impact and necessary changes and in encouraging change in competing companies. LCAs allow for the comparison of products and practices which can then be used for decision-making and determining areas of change. However, to the best of our knowledge, there are no public LCAs available on functional foods, and so the intention is to encourage further studies through the sharing of this first one.

TCI Co., Ltd. is an original design manufacturer (ODM) in the biotechnology industry for functional foods and skincare products. Due to being concerned with its carbon footprint as well as noticing an absence of LCAs in the industry, TCI has conducted LCAs on two of its functional food products. Biotechnology uses life sciences to develop products that are advantageous to humans, from the improvement of societal practices, like agriculture, to the strengthening of human health. Functional foods are those which have increased physiological benefits through biotechnology which Zeisel [1] defines as "those diet supplements that deliver a concentrated form of a presumed bioactive agent from a food". In 2019, the functional food market size was valued at US\$177.77 billion, and 
by 2027 , it is estimated to reach US $\$ 267.92$ billion, registering a compound annual growth rate (CAGR) of $6.7 \%$ from 2021 to 2027 [2]. Given this predicted growth, it is important to understand the environmental impacts of functional foods, which are currently lacking.

TCI is a member of RE100, a global initiative led by the Climate Group in which globally influential companies commit to $100 \%$ renewable electricity. TCI is also Asia's first biotechnology company with carbon emission reduction targets that are recognized by the Science-Based Targets Initiative (SBTi) [3]. A life cycle carbon footprint assessment is an important tool in reaching TCI's net-zero carbon production goals as well as presenting research on GHG emissions of functional foods for comparison of other products in the biotechnology and functional foods industry. TCI chose to first study two products"Plant Punch Fruits and Vegetables Ferment Powder" and "Liquid Collagen"-which use common manufacturing practices and have a strong and growing demand. By knowing their carbon footprint, TCI was also able to offset its carbon emissions and receive a Certificate of Carbon Neutrality for both products.

\section{Consumer Demand for Sustainability in the Biotechnology Industry}

As the understanding of biotechnology expands, consumers are demanding more scientifically advanced products [4]. Furthermore, there is an increasing growth of consumer awareness and concern for social and environmental issues. Based on a 2020 study of 18,980 consumers in 28 countries conducted by the IBM Institute for Business Value, $57 \%$ of consumers are willing to change their purchasing habits to help reduce negative environmental impact. All ages in the study selected sustainability, environmental, and/or personal wellness as significant considerations in choosing brands [5]. Between 2015-2019, sustainable consumer packaged goods (CPG) products had a market growth of $54.7 \%$ which was 7.1 times faster than non-sustainability-marketed products [6].

Not only do companies need to align with sustainability initiatives to ensure customer retention, but they should also do so with transparency to foster customers' trust. $71 \%$ of participants who indicated that traceability is very important in the same IBM study also said they are willing to pay a premium for products of companies that practice transparency. Currently, sustainable products boast a premium of $39.5 \%$ over conventionally-marketed products [5].

Drawing from just two of many examples of major functional food brands and their commitment to sustainability in response to consumer demand, Shiseido Group "responds to the increasing number of consumers that put social responsibility and environmental impact at the top of their purchasing decisions by promoting brands that focus on sustainability" [7]. To address sustainability concerns, The Bountiful Company, formerly Nature's Bounty Co., "[seeks] ways to minimize [its] environmental footprint throughout [its] supply chain including reducing, reusing, and recycling materials and ensuring responsible energy and water use [8]". Conducting a life-cycle assessment is an important step in reducing a company's environmental footprint and, consequently, increasing consumer loyalty and benefiting from higher premiums.

\section{Methodology}

The focus of this life-cycle assessment is on the carbon footprint of two products at both their raw material and manufacturing stages. Not only do these LCAs allow TCI to understand the environmental impact of its products, but they can now also be offered as a reference to other businesses producing similar products. Sharing of knowledge and practices in the biotechnology industry benefits all when working to reduce negative environmental impacts. Although TCI has various product lines from drinks, powder and liquid supplements, capsules, lozenges, to facial masks, TCI chose a powder and a liquid product as its research targets since these use common manufacturing practices and have large and growing markets, especially in Asia. 


\subsection{Life Cycle Assessment}

The LCA software, SimaPro (version 9.1.1.1, PRé Sustainability B.V., Amersfoort, The Netherlands) and the Intergovernmental Panel on Climate Change's (IPCC) greenhouse gas emissions assessment method, specifically IPCC 2013 GWP 100a v1.03, were used to calculate emissions. This method uses IPCC's Global Warming Potential (GWP) metric that "integrates the radiative forcing (RF) of a substance over a chosen time horizon, relative to that of [carbon dioxide $\left.\left(\mathrm{CO}_{2}\right)\right][9] "$ ". Therefore, through GWP, this study compares all greenhouse gases listed under IPCC using the carbon dioxide equivalent $\left(\mathrm{CO}_{2} \mathrm{e}\right)$ value.

An LCA, however, only shows a portion of the emissions generated in the entire life cycle of these products, as it is difficult to accurately assess post-consumer stages. While it is possible to perform LCAs on environmental impacts aside from emissions, such as land use, natural resources use, and waste, in these LCAs, TCI solely looks at the carbon footprint. Due to variations in LCA approaches, LCA results may also be challenging to compare and communicate.

$\mathrm{CO}_{2} \mathrm{e}$ emissions for both products are broken down by their raw material stage and manufacturing stage, as seen in Figure 1, including transportation during and between each phase. The raw material stage considers the equipment consumption and processes taken by TCI and its supply chain to acquire materials needed for the product and the product's packaging. The manufacturing stage's variables are all those that use energy in the manufacturing, packaging, and waste collection of the products.

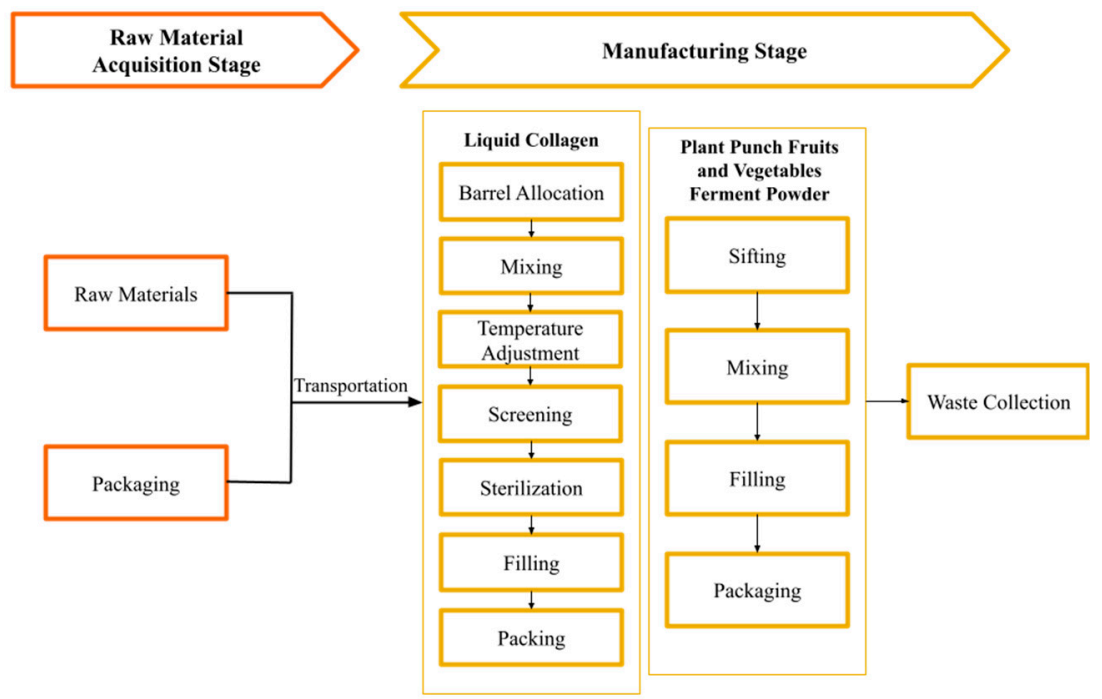

Figure 1. Processes for Plant Punch Fruits and Vegetables Ferment Powder, and Liquid Collagen.

\subsection{Plant Punch Fruits and Vegetables Ferment Powder}

TCI's Plant Punch Fruits and Vegetables Ferment Powder comes in a sachet that contains 88 types of fermented fruits and vegetables and probiotics. In total, 21 raw materials are needed for the product and 9 are needed to produce 1 aluminum sachet. Packaging materials include corrugated board, low-density polyethylene (LDPE), and kraft paper.

The probiotic segment accounted for more than one-quarter of the global functional food market share in 2019, and it is expected to sustain its share until 2027, with a compound annual growth rate of $7.9 \%$. While the Asia Pacific is the largest market, North America is predicted to grow considerably in the global market. This is largely attributed to increasing awareness of the benefits of fermented drinks in enhancing the immune system and improving the digestive system [10]. 


\subsection{Liquid Collagen}

The second product, Liquid Collagen, contains deep-sea fish collagen and elastin collagen. Collagen improves the contours of the skin, accelerates the healing of wounds, and revitalizes the skin. The global collagen supplement market generated $\$ 1.82$ billion in 2019 , and it is expected to garner $\$ 3.01$ billion by 2027 [11].

Other raw materials used in the product include meats, fruits, organic chemicals, and glucose, totaling 17 types of materials. For the packaging, 11 types of raw materials were needed, including uncoated flat glass, corrugated board, LDPE, and kraft paper, to produce 1 glass bottle with a cap.

\section{Results}

Figure 2 shows the LCA results focusing on GHG emissions. The unit for the Plant Punch Fruits and Vegetables Ferment Powder is one sachet at $12 \mathrm{~g}$. With a sample size of 48,750 sachets, the emissions at the raw material stage and manufacturing stage were $44.98 \mathrm{~g} \mathrm{CO}_{2} \mathrm{e} /$ sachet and $12.80 \mathrm{~g} \mathrm{CO}_{2} \mathrm{e} /$ sachet, respectively. The total emissions are $57.78 \mathrm{~g}$ $\mathrm{CO}_{2} \mathrm{e} /$ sachet.

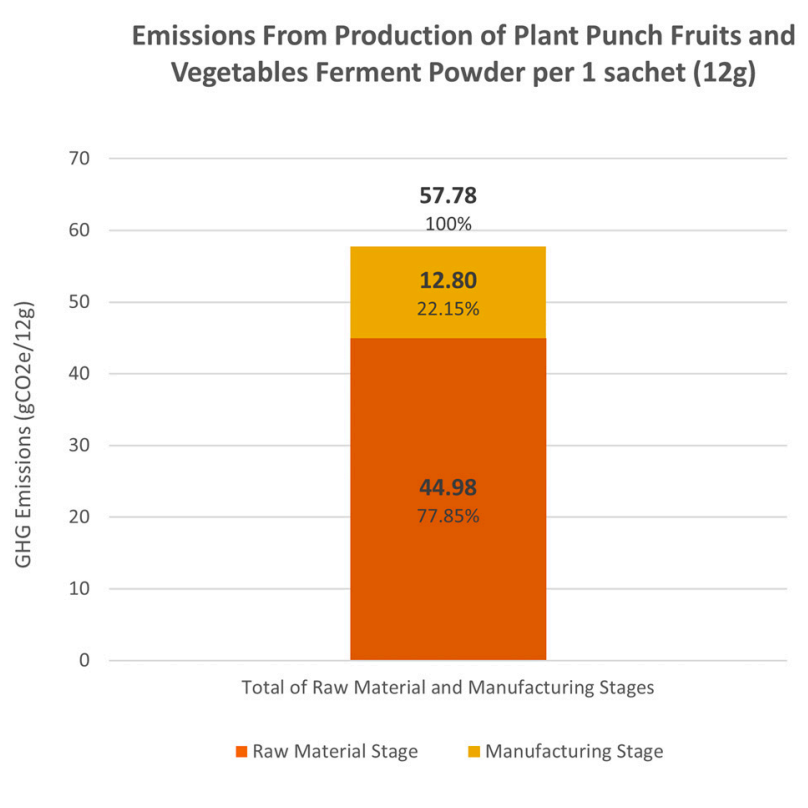

(a)

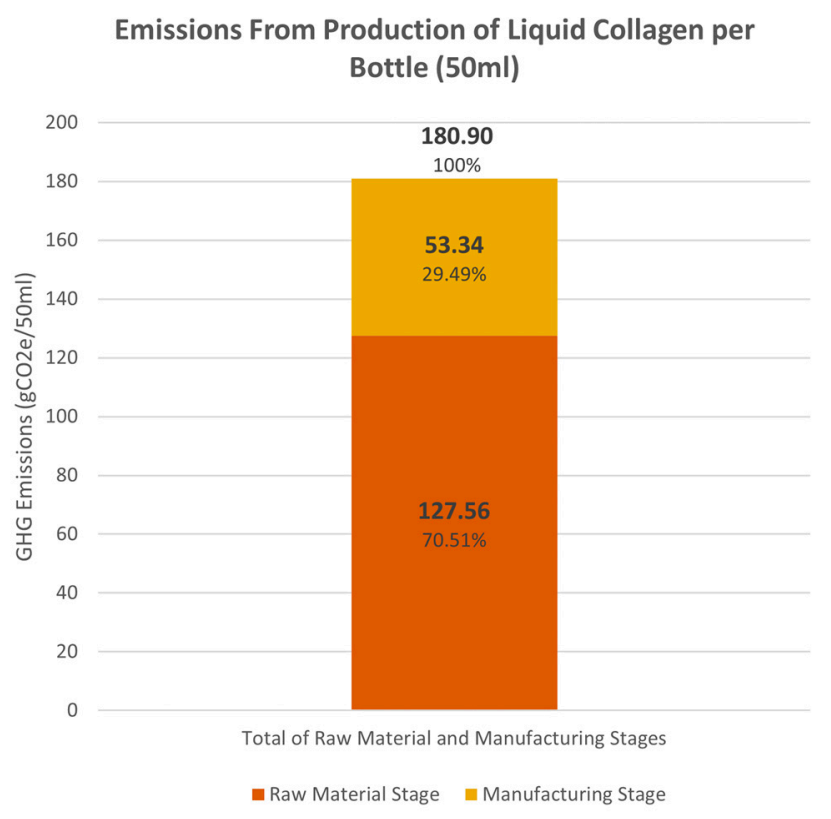

(b)

Figure 2. GHG Emissions ( $\mathrm{g} \mathrm{CO}_{2} \mathrm{e}$ ) of products at The Raw Material and Manufacturing Stages with Percentages of Total Emissions. (a) Emissions of Plant Punch Fruits and Vegetables Ferment Powder; and (b) Emissions of Liquid Collagen.

The unit for the Liquid Collagen is one bottle at $50 \mathrm{~mL}$. With a sample size of 4,715,548 bottles, the emissions at the raw material stage and manufacturing stage were $127.56 \mathrm{~g} \mathrm{CO}_{2} \mathrm{e} / \mathrm{bottle}$ and $53.34 \mathrm{~g} \mathrm{CO}_{2} \mathrm{e} /$ bottle, respectively. The total emissions are $180.90 \mathrm{~g} \mathrm{CO}_{2} \mathrm{e} /$ bottle.

The raw material stage for the Plant Punch Fruit and Fermented Vegetables and the Liquid Collagen accounted for $77.85 \%$ and $70.51 \%$ of the total greenhouse gas emissions, respectively. This shows the importance of suppliers in their contribution to the overall environmental impact of a product. TCI states that it is working with its suppliers to meet its goal of developing net-zero carbon products [12], and these LCA results support the need to ensure a low emissions supply chain.

For both products, the emission-driving variables in the manufacturing stage were the use of petrol and refrigerants. The raw materials that generated the highest emissions were LDPE for packaging and citric acid for the products. 


\section{Discussion}

The LCAs in this study focused on greenhouse gas emissions generated during the raw material and manufacturing stages for its Plant Punch Fruit and Fermented Vegetables and Liquid Collagen products. Our findings showed that most overall emissions were a result of acquiring raw materials and packaging materials. For both products, the accumulation of the abundance of raw materials needed outweighed that of the manufacturing process which had higher emissions values for each variable, but significantly fewer variables. In future studies, we encourage greater detail of the findings, such as a breakdown of the materials and their emission values within each stage.

Emissions from the raw material stage being $70 \%$ and higher of the total underscores the importance of supply chains in a product's environmental impact. TCI must encourage its supply chain to lower emissions also, and so it should communicate and work with its suppliers to understand how they can reduce emissions. As an example of how to do so, we can look at the RE100 initiative, which TCI has committed to. Many of its members, like Apple, have enforced all their suppliers to use renewable energy. However, these companies also have a responsibility to support their suppliers in their efforts to reduce emissions, such as offering consultations on how to procure renewable energy.

Regarding the biotechnology industry, "there are only a few studies on the applications [of life cycle sustainability assessments] in this field even though there is a huge need for sustainability and life cycle assessment decision support in research, industry, and politics" [13]. Even more scarce is the publication of LCAs on functional foods, to which we could find none. Hopefully through TCI being one of the first, if not the first, in the industry to share its findings, more companies in the industry will do the same to improve transparency and knowledge sharing. More studies in the industry would mean a greater ability to compare emissions. However, a challenge with LCAs is the variability in approaches. Given this, it is recommended that an LCA approach be set for the industry, as the European Commission had set for the construction industry through policy [14]. Ortiz et al. has demonstrated how multiple case studies of LCAs, despite some variability, can still be compared and reviewed to assess the best approaches [14].

\section{Conclusions}

There is a lack of understanding of the environmental impacts of the biotechnology and functional foods industries. Through this study, we share LCA findings, taking TCI as a case study, to exchange information with others in the industry and work towards more sustainable manufacturing practices. In increasing transparency of environmental impacts, particularly with the use of LCAs, companies, and stakeholders can compare products and establish environmental standards for decision-making purposes. Evaluating and reducing GHG emissions should not only be a concern for brands for ethical and environmental purposes, but also for business' sake. Not only are functional foods estimated to grow in the market, but so are sustainability-marketed products, and with such products, a higher premium and a possible increase in consumers who are already demanding more sustainable products.

This study is simply the first in what we hope will become a batch of many case studies in the industry to review and achieve a better understanding of the environmental impacts.

Author Contributions: Conceptualization, A.L. and S.-F.L.; methodology, A.L. and S.-F.L.; formal analysis, A.L., Y.W., S.-F.L.; data curation, A.L., Y.W., S.-F.L.; writing—original draft preparation, A.L., Y.W.; writing-review and editing, A.L., Y.W., S.-F.L.; visualization, A.L.; supervision, S.-F.L.; funding acquisition, S.-F.L. All authors have read and agreed to the published version of the manuscript.

Funding: This research was funded by TCI. Co., Ltd.

Institutional Review Board Statement: Not applicable.

Informed Consent Statement: Not applicable. 
Data Availability Statement: The data presented in this study are available on request from the corresponding author. The data are not publicly available due to privacy concerns.

Conflicts of Interest: The authors declare no conflict of interest.

\section{References}

1. Zeisel, S.H. Regulation of 'Nutraceuticals. Science 1999, 285, 1853-1855. [CrossRef] [PubMed]

2. Functional Food Market by Ingredient (Probiotics, Minerals, Proteins \& Amino Acids, Prebiotics, \& Dietary Fibers, Vitamins and Others), Product (Bakery \& Cereals, Dairy Products, Meat, Fish \& Eggs, Soy Products, Fats \& Oils and Others), Application (Sports Nutrition, Weight Management Clinical Nutrition, Cardio Health, and Others): Global Opportunity Analysis and Industry Forecast 2021-2027. Available online: https:/ / www.alliedmarketresearch.com/functional-food-market (accessed on 16 June 2021).

3. TCI Co., Ltd. Becomes Asia's First Biotechnology Company Whose Climate Ambitions Are Validated by SBTi. Available online: https: / / www.prnewswire.com/news-releases/tci-co-ltd-becomes-asias-first-biotechnology-company-whose-climateambitions-are-validated-by-sbti-301277521.html (accessed on 29 June 2021).

4. Zappelli, C.; Barbulova, A.; Apone, F.; Colucci, G. Effective Active Ingredients Obtained through Biotechnology. Cosmetics 2016, 3, 39. [CrossRef]

5. Cheung, J. Research Insights: Meet the 2020 consumer driving change. Available online: https://www.ibm.com/downloads/ cas / EXK4XKX8 (accessed on 20 June 2021).

6. Sustainable Market Share Index: Research on 2015-2020 IRI Purchasing Data Reveals Sustainability Drives Growth, Survives the Pandemic. Available online: https:/ / www.stern.nyu.edu/sites/default/files/assets / documents / 2020\%20Sustainable\%20 Market\%20Share\%20Index.pdf (accessed on 17 June 2021).

7. Shiseido. Developing Sustainable Products (Formula and Packaging). Available online: https://corp.shiseido.com/en/ sustainability / env / action3.html (accessed on 25 June 2021).

8. The Bountiful Company Foundation. Available online: https://www.bountifulcompany.com/csr/ (accessed on 25 June 2021).

9. Myhre, G.; Shindell, D.; Bréon, F.-M.; Collins, W.; Fuglestvedt, J.; Huang, J.; Koch, D.; Lamarque, J.-F.; Lee, D.; Mendoza, B.; et al. Anthropogenic and Natural Radiative Forcing. In Climate Change 2013: The Physical Science Basis; Stocker, T.F., Qin, D., Plattner, G.-K., Tignor, M., Allen, S.K., Boschung, J., Nauels, A., Xia, Y., Bex, V., Midgley, P.M., Eds.; Cambridge University Press: Cambridge, UK; New York, NY, USA, 2013; pp. 659-691.

10. Probiotics Market Size, Share \& COVID-19 Analysis, By Microbial Genus (Lactobacillus, Bifidobacterium, and Yeast), Application (Functional Foods \& Beverages, Dietary Supplements, and Animal Feed), Distribution Channel (Supermarkets/Hypermarkets, Pharmacies/Health Stores, Convenience Stores, Online Retail, and Others), and Regional Forecast, 2020-2027. Available online: https: / / www.fortunebusinessinsights.com/industry-reports/probiotics-market-100083 (accessed on 16 June 2021).

11. Collagen Supplement Market by Source (Marine \& Poultry, Porcine, and Bovine), Form (Pills \& Gummies, Powder, and Liquid/Drinks), and Concentration (Pharmacy, Specialty Store, and Online Store): Global Opportunity Analysis and Industry Forecast, 2021-2027. Available online: https:/ / www.alliedmarketresearch.com/collagen-supplement-market-A10853 (accessed on 16 June 2021).

12. TCI Co., Ltd. Sustainability Report 2019. Available online: https://www.tci-bio.com/Documents/CSR_Reports/2019 _Sustainability_Report_EN.pdf (accessed on 16 June 2021).

13. Fröhling, M.; Hiete, M. Sustainability and Life Cycle Assessment in Industrial Biotechnology: A Review of Current Approaches and Future Needs. In Sustainability and Life Cycle Assessment in Industrial Biotechnology; Fröhling, M., Hiete, M., Eds.; Springer Nature: Cham, Switzerland, 2020; p. 191.

14. Ortiz, O.; Castells, F.; Sonnemann, G. Sustainability in the Construction Industry: A Review of Recent Developments Based on LCA. Constr. Build. Mater. 2009, 23, 28-39. [CrossRef] 